\title{
Relações treonina:lisina digestíveis e níveis de energia líquida para suínos em crescimento e terminação ${ }^{1}$
}

\section{Diovani Paiano², Ivan Moreira ${ }^{3}$, Antonio Claudio Furlan ${ }^{3}$, Paulo Levi de Oliveira Carvalho ${ }^{4}$, Ilton Shiguemi Kuroda Junior ${ }^{5}$, Elias Nunes Martins ${ }^{3}$}

1 Pesquisa parcialmente financiada pela CAPES.

2 Departamento de Zootecnia, Universidade do Estado de Santa Catarina, Centro de Educação Superior do Oeste. Rua Benjamin Constant, 84E, CEP: 89802-200, Chapecó - SC, Brasil.

${ }^{3}$ Departamento de Zootecnia, Universidade Estadual de Maringá-UEM, Av. Colombo, 5790, CEP: 87020-900, Maringá - PR, Brasil.

${ }^{4}$ Programa de Pós-graduação em Zootecnia, UEM.

5 Curso de Graduação em Zootecnia, UEM.

RESUMO - Dois experimentos foram conduzidos para estudar o efeito de cinco relações treonina:lisina digestíveis (TL) sobre o balanço de nitrogênio em suínos em crescimento e de cinco níveis de energia líquida (EL) sobre o desempenho de suínos em crescimento-terminação. No primeiro experimento, foram utilizados 15 suínos machos castrados com peso inicial de 37,0 \pm 2,6 kg, híbridos comerciais de média a alta deposição de tecido magro, distribuídos em delineamento inteiramente casualizado, com cinco tratamentos (relações treonina:lisina digestíveis de 0,574; 0,624; 0,673; 0,722 e 0,772 em rações formuladas com baixo nível de proteína, 14,7\%) e três repetições. A TL influenciou de forma quadrática a proteína bruta absorvida (PBA) e o nitrogênio da uréia plasmática (NUP), os quais apresentaram melhores resultados com a TL de 0,658 (média do PBA e NUP). No segundo experimento, foram estudados cinco níveis de EL em rações com a relação TL de 0,658. Utilizaram-se 40 suínos (20 machos castrados e 20 fêmeas) com 30,2 \pm 1,3 kg, de características semelhantes às dos utilizados no experimento para balanço de nitrogênio, distribuídos em delineamento inteiramente casualizado, em esquema fatorial $5 \times 2$, composto de cinco níveis de energia líquida $(2.410 ; 2.450 ; 2.490 ; 2.530$ ou $2.570 \mathrm{kcal} / \mathrm{kg})$ e dois sexos, com um animal por baia. Na fase de terminação e no período total, o aumento nos níveis de EL ocasionou redução do consumo diário de ração (CDR), melhora da conversão alimentar (CA) e acréscimo na deposição de gordura. A relação TL de 0,658 melhora a retenção de nitrogênio e níveis crescentes de energia líquida diminuem o CDR e melhoram a CA, mas podem aumentar a deposição de gordura em suínos.

Palavras-chave: balanço de nitrogênio, carcaça, desempenho, energia, proteína ideal

\section{Digestible threonine:lysine ratios and net energy levels in growing/finishing pigs}

ABSTRACT - Two experiments were carried out to evaluate the effect of five digestible threonine:lysine ratios (TL) on the nitrogen balance of growing pigs and five levels of net energy (NE) on growing-finishing pigs performance. In the first experiment, 15 high-lean commercial crossbred barrows, with initial weight of $37.0 \pm 2.6 \mathrm{~kg}$, were allotted to a completely randomized design, with five diets (digestible threonine:lysine ratio of $0.574,0.624,0.673,0.722$, and 0.772, in low protein diets, 14.7\%) and three replications. Absorbed crude protein (ACP) and plasma urea nitrogen (PUN) showed a quadratic effect and the best threonine:digestible lysine ratio was 0.658 (mean of ACP and PUN). In the second experiment, five EL dietary levels were evaluated with digestible threonine:lysine ratio of 0.658. Forty pigs (20 barrows and 20 gilts) with $30.2 \pm 1.3 \mathrm{~kg}$ were allotted to a completely randomized design, as a $5 \times 2$ factorial arrangement, composed of five levels of $\mathrm{NE}(2.410,2.450,2.490,2.530$, or $2.570 \mathrm{Mcal} / \mathrm{kg})$ and two sexes, with one animal per cage. In the finishing phase and total period, increasing NE levels reduced feed intake (FI), improved feed:gain ratio (FGR) and increased fat deposition. Digestible threonine:lysine ratio of 0.658 improves nitrogen retention and the increasing net energy levels decrease FI and improve FGR, but may increase fat deposition in pigs.

Key Words: carcass, energy, ideal protein, nitrogen balance, performance 


\section{Introdução}

A grande importância da criação de suínos é a produção de proteína para consumo humano. Para que a síntese protéica ocorra, é necessário que todos os aminoácidos essenciais estejam disponíveis em quantidade e proporção que atendam suas necessidades, que variam de acordo com o seu potencial genético.

Entre os aminoácidos essenciais, a lisina e a treonina são considerados, respectivamente, o primeiro e o terceiro aminoácidos limitantes para suínos alimentados com rações à base de milho e farelo de soja (NRC, 1998). As exigências nutricionais de treonina, assim como a relação treonina:lisina indicadas na literatura (Defa et al., 1999; NRC, 1998; Rodrigues et al., 2001; Rostagno et al., 2005), podem variar de acordo com as condições experimentais, o estágio fisiológico, o sexo, o potencial genético e as diferenças no nível de proteína e energia das dietas experimentais (Rodrigues et al., 2001).

Como recurso para reduzir a poluição ambiental, a excreção de nitrogênio e os custos das rações, tem-se adotado o conceito de proteína ideal na formulação das rações, que consiste na redução do teor de proteína e da adição de aminoácidos sintéticos. Nesse sentido, os recentes avanços na determinação das exigências em aminoácidos dos suínos e a utilização do conceito de proteína ideal têm permitido a utilização de dietas com menores teores de proteína bruta sem o comprometimento do desempenho (Le Bellego et al., 2001; Noblet, 1996).

Entretanto, alguns autores, como Kerr et al. (1995), afirmam que dietas formuladas com base no conceito de proteína ideal, com perfil adequado de aminoácidos e menor teor de proteína, resultam em carcaças com maior teor de gordura. A redução dos níveis de proteína bruta, com melhor relação entre os aminoácidos, reduz a energia gasta pelo animal para digestão e para excreção via urina da uréia resultante da oxidação do excesso de aminoácidos (ciclo da uréia). Além da redução da oxidação dos aminoácidos, ocorrem menor turnover das proteínas corporais e redução da produção de calor (Noblet et al., 1987). Esses fatores, combinados, podem resultar em dietas com maior teor de energia líquida (EL) e suínos com carcaça de baixa qualidade.

A utilização do sistema de energia líquida para o cálculo de dietas de baixo teor de proteína bruta, devidamente suplementadas com aminoácidos, pode evitar a deposição indesejável de gordura na carcaça (Le Bellego et al., 2001). O sistema de energia líquida pode atender melhor às exigências dos animais e reduzir os custos energéticos da ingestão e digestão dos alimentos (Noblet, 1996).
Assim, realizou-se este estudo com os objetivos de determinar a melhor relação treonina:lisina digestíveis (TL) para aproveitamento dos aminoácidos da dieta e verificar o efeito de diversos níveis de energia líquida, com a relação TL previamente determinada, sobre o desempenho e a qualidade da carcaça e da carne de suínos em crescimento e terminação.

\section{Material e Métodos}

Foram conduzidos dois experimentos para determinar a melhor relação treonina:lisina digestíveis (TL) e os efeitos dos níveis de energia líquida da dieta para suínos em crescimento e terminação. Os experimentos foram conduzidos no Setor de Suinocultura da Fazenda Experimental de Iguatemi (FEI), pertencente à Universidade Estadual de Maringá (UEM), localizada no estado do Paraná $\left(23^{\circ} 21^{\prime}\right.$ S, $52^{\circ} 04 ' \mathrm{~W}$, a $564 \mathrm{~m}$ de altitude).

No primeiro experimento, para determinação do balanço de nitrogênio, foram utilizados 15 suínos machos castrados, híbridos comerciais com médio a alto potencial de deposição de carne magra, com 37,0 $\pm 2,6 \mathrm{~kg}$ de peso corporal, alojados em gaiolas para estudos de metabolismo do tipo pekas. As temperaturas, mínima e máxima, médias registradas durante o primeiro experimento foram de $21,4 \pm 2,9$ e $27,2 \pm 4,4^{\circ} \mathrm{C}$, respectivamente. Utilizou-se um período de sete dias de adaptação ao ambiente, às rações e ao manejo alimentar, seguido de cinco dias de coleta total de fezes e urina.

Foram formuladas cinco rações com base no conceito de proteína ideal, de acordo com as relações de aminoácidos determinadas para suínos de médio a alto potencial para deposição de carne magra ( $325 \mathrm{~g} /$ dia) na fase de crescimento (45 kg), indicadas pelo NRC (1998). O teor de proteína bruta da ração foi reduzido em $3 \%$, resultando em dietas com baixo teor de proteína bruta $(14,7 \%)$, calculadas para serem isoenergéticas e isonutritivas (Tabela 1), exceto em treonina, adotando-se a lisina digestível como padrão e cinco relações treonina:lisina digestíveis(TL): 0,574;0,624;0,673;0,722e0,772.

A composição de aminoácidos do milho e do farelo de soja utilizados na formulação das rações foi previamente analisada em cromatografia líquida de alta performance (HPLC). Os valores de aminoácidos digestíveis foram estimados utilizando-se os coeficientes de digestibilidade verdadeira, propostos por Rostagno et al. (2005). Os valores de energia (digestível, metabolizável e líquida) foram calculados com base nos valores propostos por Rostagno et al. (2005) e nos resultados da análise dos ingredientes. Os valores de cálcio e fósforo foram analisados segundo metodologia descrita por Silva \& Queiroz (2002). 
Tabela 1 - Composição das rações experimentais fornecidas na fase de crescimento $(30-60 \mathrm{~kg})$

\begin{tabular}{|c|c|c|c|c|c|}
\hline \multirow[t]{2}{*}{ Item $(\%)$} & \multicolumn{5}{|c|}{ Relação treonina:lisina digestíveis } \\
\hline & 0,574 & 0,624 & 0,673 & 0,722 & 0,772 \\
\hline Milho & 81,045 & 81,045 & 81,045 & 81,045 & 81,045 \\
\hline Farelo de soja & 15,35 & 15,35 & 15,35 & 15,35 & 15,35 \\
\hline Amido & 0,000 & 0,016 & 0,032 & 0,047 & 0,063 \\
\hline Óleo de soja & 0,489 & 0,489 & 0,489 & 0,489 & 0,489 \\
\hline Fosfato bicálcico & 0,640 & 0,640 & 0,640 & 0,640 & 0,640 \\
\hline Calcário & 0,896 & 0,896 & 0,896 & 0,896 & 0,896 \\
\hline 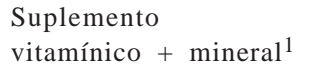 & 0,500 & 0,500 & 0,500 & 0,500 & 0,500 \\
\hline Sal comum & 0,400 & 0,400 & 0,400 & 0,400 & 0,400 \\
\hline L-lisina $\mathrm{HCl}$ & 0,237 & 0,237 & 0,237 & 0,237 & 0,237 \\
\hline L-triptofano & 0,016 & 0,016 & 0,016 & 0,016 & 0,016 \\
\hline L-treonina & 0,014 & 0,056 & 0,098 & 0,140 & 0,182 \\
\hline Ácido glutâmico & 0,413 & 0,355 & 0,297 & 0,240 & 0,182 \\
\hline \multicolumn{6}{|l|}{ Composição calculada } \\
\hline Proteína bruta, $\%^{2}$ & 14,70 & 14,70 & 14,70 & 14,70 & 14,70 \\
\hline $\begin{array}{l}\text { Energia digestível, } \\
\mathrm{kcal} / \mathrm{kg}^{3}\end{array}$ & 3.400 & 3.400 & 3.400 & 3.401 & 3.401 \\
\hline $\begin{array}{l}\text { Energia metabolizável, } \\
\mathrm{kcal} / \mathrm{kg}^{3}\end{array}$ & 3.258 & 3.259 & 3.259 & 3.259 & 3.259 \\
\hline $\begin{array}{l}\text { Energia líquida, } \\
\mathrm{kcal} / \mathrm{kg}^{3}\end{array}$ & 2.513 & 2.513 & 2.513 & 2.512 & 2.512 \\
\hline Lis digestível, $\%^{2}$ & 0,810 & 0,810 & 0,810 & 0,810 & 0,810 \\
\hline Met + Cis digestível, $\%^{2}$ & 0,470 & 0,470 & 0,470 & 0,470 & 0,470 \\
\hline Tre digestível, $\%^{2}$ & 0,465 & 0,505 & 0,545 & 0,585 & 0,625 \\
\hline Trp digestível, \% ${ }^{2}$ & 0,150 & 0,150 & 0,150 & 0,150 & 0,150 \\
\hline Arg digestível, $\%^{2}$ & 0,818 & 0,818 & 0,818 & 0,818 & 0,818 \\
\hline Cálcio, \% ${ }^{4}$ & 0,548 & 0,548 & 0,548 & 0,548 & 0,548 \\
\hline Fósforo disponível, \% ${ }^{3}$ & 0,210 & 0,210 & 0,210 & 0,210 & 0,210 \\
\hline
\end{tabular}

1 Suplemento vitamínico e mineral para suínos em crescimento.

2 Valores calculados com base na composição em aminoácidos analisados e nos valores de digestibilidade dos aminoácidos dos ingredientes propostos por Rostagno et al. (2005).

3 Valores calculados com base na composição analisada e nos valores propostos por Rostagno et al. (2005).

4 Valores analisados segundo metodologias descritas por Silva \& Queiroz (2002).

Os animais foram distribuídos em delineamento inteiramente ao acaso com cinco tratamentos (cinco relações TL) e três repetições.

A quantidade de ração fornecida foi definida com base no peso metabólico $\left(\mathrm{kg}^{0,75}\right)$ de cada suíno e no consumo médio dos animais no período de adaptação. $\mathrm{O}$ arraçoamento foi realizado às 8 e 16 h com o fornecimento de $55 \%$ do total de ração pela manhã e 45\% no período da tarde (proporção definida com base nos consumos entre manhã e tarde do período de adaptação). A água foi oferecida na proporção de 2,5 mL de água/g de ração no próprio comedouro, após o consumo da ração.

Utilizou-se o método de coleta total de excretas, com óxido de ferro como marcador fecal ( $2 \%$ de $\left.\mathrm{Fe}_{3} \mathrm{O}_{2}\right)$. As fezes foram coletadas uma vez ao dia, acondicionadas em sacos plásticos e armazenadas em freezer $\left(-18^{\circ} \mathrm{C}\right)$. A urina dos suínos foi coletada em baldes de plástico contendo $20 \mathrm{~mL}$ de HCl 1:1 para evitar a proliferação bacteriana e possíveis perdas por volatilização. A determinação da composição química das fezes, dos alimentos e das rações foi realizada segundo metodologias descritas por Silva \& Queiroz (2002).

Os valores de proteína bruta consumida (PBC), proteína bruta excretada nas fezes (PBF) e excretada na urina (PBU) foram obtidos pela multiplicação dos teores de proteína pelas quantidades de ração consumida e de fezes e urina excretada, respectivamente. A partir desses valores, calcularam-se a proteína bruta retida $(\mathrm{PBR}=\mathrm{PBC}-\mathrm{PBF}-$ PBU), a utilização líquida de proteína (ULP = PBR/PBC) e o valor biológico da proteína dietética $(\mathrm{VBPD}=\mathrm{PBR} /(\mathrm{PBC}$ PBF)), segundo Adeola (2001). Foram colhidas amostras de sangue no final do experimento, pela veia cava cranial para determinação do nitrogênio da uréia plasmática - NUP (Marsh et al., 1965).

Os resultados obtidos foram submetidos à análise de regressão polinomial de acordo com o seguinte modelo estatístico: $\mathrm{Y}_{i j}=\mu+\mathrm{N}_{i}+\mathrm{e}_{i j}$, em que: $\mathrm{Y}_{i j}=$ valor das variáveis estudadas, relativo a cada indivíduo j recebendo a relação $\mathrm{i} ; \mu=$ constante geral; $\mathrm{N}_{i}=$ relações $\mathrm{TL}$, em que $\mathrm{i}=0,574 ; 0,624 ; 0,673 ; 0,722$ e 0,$772 ; \mathrm{e}_{i j}=$ erro-aleatório associado a cada observação.

Os graus de liberdade das relações treonina:lisina digestíveis foram desdobrados em polinômios ortogonais. No caso das variáveis que apresentaram efeito quadrático, as equações obtidas foram derivadas para obtenção do ponto de máximo ou de mínimo e obtenção da melhor relação treonina:lisina digestíveis.

No segundo experimento, para avaliação dos efeitos dos níveis de energia líquida sobre o desempenho de suínos nas fases de crescimento e terminação, utilizaram-se 40 suínos (20 machos castrados e 20 fêmeas) híbridos comerciais, da mesma linhagem utilizada no experimento de balanço de

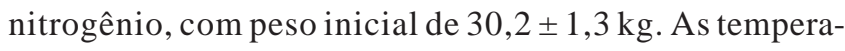
turas mínima e máxima registradas no período experimental foram de $17,4 \pm 3,9^{\circ} \mathrm{C}$ e $27,0 \pm 3,5^{\circ} \mathrm{C}$. As umidades relativas do ar médias do período experimental, pela manhã e pela tarde, foram de 83,3 $\pm 10,1 \%$ e 58,3 \pm 14,8\%, respectivamente.

Os suínos foram distribuídos em delineamento inteiramente casualizado, em esquema fatorial $(5 \times 2)$, com cinco níveis de energia líquida $(2.410 ; 2.450 ; 2.490 ; 2.530$ e $2.570 \mathrm{kcal}$ de energia líquida/kg) (Tabelas 2 e 3) e dois sexos (machos castrados e fêmeas), com quatro repetições, de modo que a unidade experimental foi constituída de uma baia com um suíno. As exigências nutricionais utilizadas no cálculo das rações utilizadas no experimento de desempenho foram estabelecidas com mesmas metodologias adotadas no experimento para estimação do balanço de nitrogênio, 
Tabela 2 - Composição das rações experimentais com relação treonina:lisina digestíveis de 0,658 fornecidas na fase de crescimento (30 a $60 \mathrm{~kg})$

\begin{tabular}{|c|c|c|c|c|c|}
\hline \multirow[b]{2}{*}{ Item, \% } & \multicolumn{5}{|c|}{ Nível de energia líquida, kcal/kg1 } \\
\hline & 2.415 & 2.455 & 2.495 & 2.535 & 2.575 \\
\hline Milho & 77,127 & 78,016 & 78,905 & 79,793 & 80,682 \\
\hline Casca de arroz & 4,270 & 3,203 & 2,135 & 1,068 & 0,000 \\
\hline Óleo de soja & 0,200 & 0,449 & 0,698 & 0,947 & 1,196 \\
\hline Fosfato bicálcico & 0,726 & 0,724 & 0,722 & 0,72 & 0,718 \\
\hline Suplemento vitamínico + mineral $^{2}$ & 0,400 & 0,400 & 0,400 & 0,400 & 0,400 \\
\hline Promotor de crescimento ${ }^{3}$ & 0,050 & 0,050 & 0,050 & 0,050 & 0,050 \\
\hline L-lisina $\mathrm{HCl}$ & 0,247 & 0,248 & 0,248 & 0,249 & 0,250 \\
\hline DL-metionina & 0,06 & 0,058 & 0,057 & 0,055 & 0,054 \\
\hline L-treonina & 0,104 & 0,104 & 0,103 & 0,102 & 0,101 \\
\hline L-triptofano & 0,016 & 0,016 & 0,016 & 0,016 & 0,016 \\
\hline Energia digestível, kcal/kg${ }^{1}$ & 3.297 & 3.343 & 3.389 & 3.435 & 3.481 \\
\hline Energia metabolizável, $\mathrm{kcal} / \mathrm{kg}^{1}$ & 3.158 & 3.202 & 3.247 & 3.292 & 3.336 \\
\hline Lisina digestível, \%5 & 0,811 & 0,811 & 0,811 & 0,811 & 0,811 \\
\hline Met+Cis digestível, $\%^{5}$ & 0,472 & 0,471 & 0,472 & 0,471 & 0,472 \\
\hline Treonina digestível, $\%^{5}$ & 0,534 & 0,535 & 0,534 & 0,534 & 0,534 \\
\hline Triptofano digestível, $\%^{5}$ & 0,151 & 0,151 & 0,151 & 0,151 & 0,151 \\
\hline Arginina digestível, \%5 & 0,798 & 0,798 & 0,798 & 0,798 & 0,798 \\
\hline Cálcio, $\%{ }^{4}$ & 0,547 & 0,547 & 0,547 & 0,547 & 0,547 \\
\hline Fósforo disponível, $\%^{6}$ & 0,213 & 0,213 & 0,213 & 0,213 & 0,213 \\
\hline
\end{tabular}

${ }^{1}$ Valores calculados com base nas análises e nos valores de energia propostos por Rostagno et al. (2005).

2 Suplemento vitamínico e mineral para suínos em crescimento.

3 Leucomicina $30 \%$.

4 Valores analisados segundo metodologias descritas por Silva \& Queiroz (2002).

5 Valores calculados com base na composição em aminoácidos analisados e nos valores de digestibilidade dos aminoácidos dos ingredientes propostos por Rostagno et al. (2005)

6 Valores calculados com base na composição analisada e nos valores propostos por Rostagno et al. (2005).

utilizando-se o peso médio de cada fase (crescimento ou terminação).

As rações, formuladas com redução de 3\% no teor de proteína bruta e para conter os níveis nutricionais definidos pelo NRC (1998) para cada uma das fases, foram fornecidas à vontade, na forma farelada, em comedouros semi-automáticos, durante todo o período do experimento. Do mesmo modo, a água foi fornecida à vontade em bebedouros do tipo chupeta.

$\mathrm{Na}$ formulação das rações, utilizou-se a relação treonina:lisina disgestíveis que melhorou os resultados no experimento de balanço de nitrogênio $(0,658)$. Utilizaram-se os coeficientes de digestibilidade verdadeira propostos por Rostagno et al. (2005) para estimar os valores de aminoácidos digestíveis dos demais ingredientes utilizados nas rações. Os valores de energia digestível, metabolizável e líquida foram calculados com base nos valores propostos por Rostagno et al. (2005) e no resultado da análise dos ingredientes. Os valores de cálcio e fósforo foram analisados no Laboratório de Nutrição Animal da Universidade Estadual de Maringá(LANA-UEM), segundo metodologias descritas por Silva \& Queiroz (2002).

Os animais foram pesados no início e ao final da fase de crescimento e quando atingiram aproximadamente $90 \mathrm{~kg}$ (terminação). Avaliaram-se o consumo diário de ração (CDR), o ganho de peso diário (GPD) e a conversão alimentar (CA). Ao final da fase de terminação, os animais foram abatidos e submetidos à avaliação de carcaça, de acordo com o método brasileiro MBCC (ABCS, 1973) e o método americano NPPC (1991). Para avaliação da perda de água por gotejamento, foram retiradas amostras do Longissimus dorsi, na região entre a $8^{\underline{a}}$ e a $10^{\mathrm{a}}$ vértebras torácicas, segundo metodologia descrita por Boccard et al. (1981). Os teores de matéria seca, matéria mineral e proteína bruta da carne foram determinados segundo metodologia descrita por Silva \& Queiroz (2002). Ao final das fases de crescimento e terminação, foram colhidas amostras de sangue para determinação do nitrogênio da uréia plasmática (NUP) utilizando-se as mesmas metodologias descritas no experimento de balanço de nitrogênio. 
Tabela 3 - Composição das rações experimentais com relação treonina:lisina digestíveis de 0,658 fornecidas na fase de terminação $(60 \mathrm{a} 90 \mathrm{~kg})$

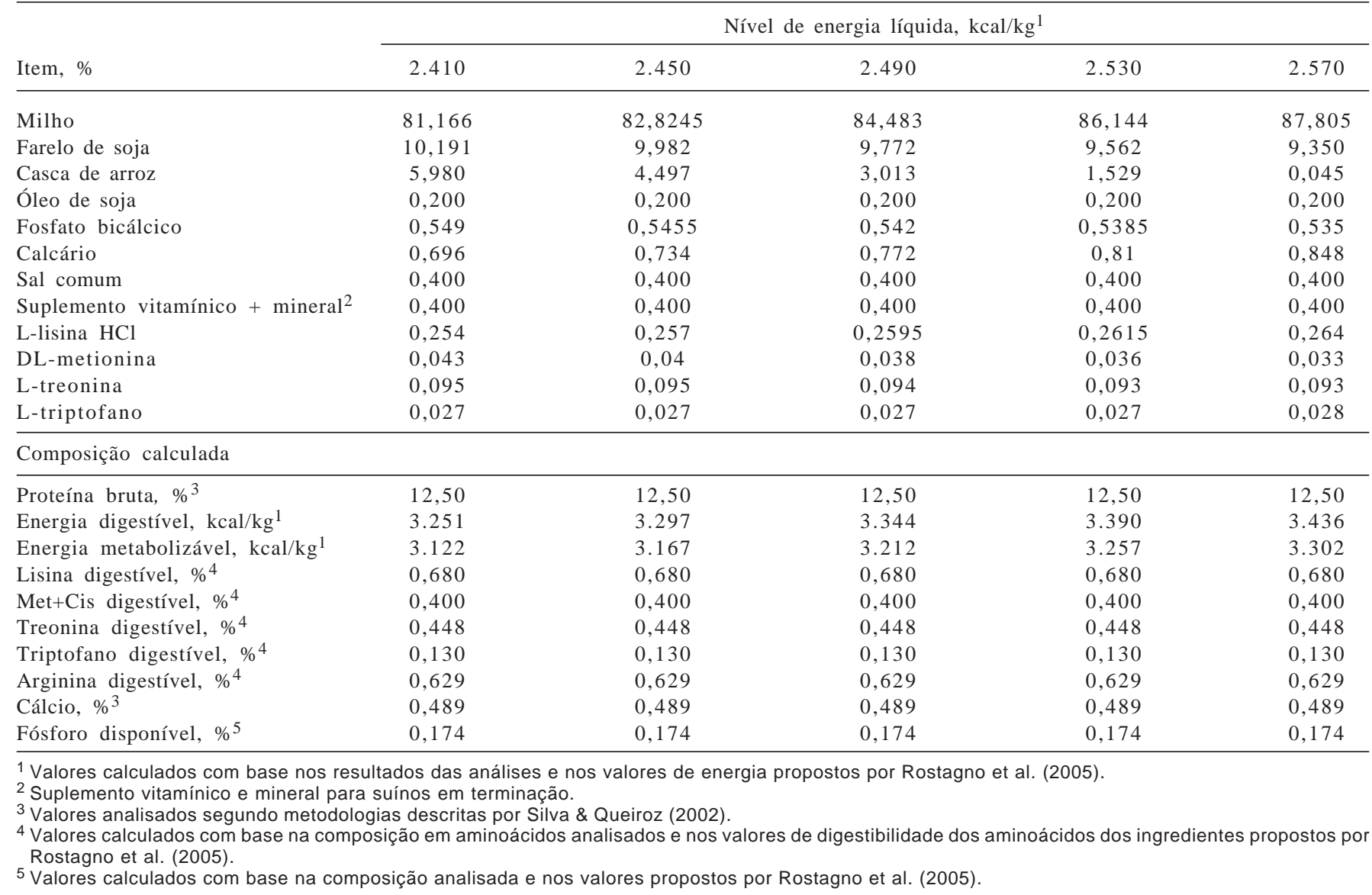

Os dados obtidos foram submetidas à análise de variância, de acordo com o modelo estatístico: $\mathrm{Y}_{i j k}=\mu+\mathrm{N}_{i}$ $+\mathrm{G}_{j}+\mathrm{NxG}+\mathrm{e}_{i j k}$, em que: $\mathrm{Y}_{i j k}=$ variáveis estudadas; $\mu=$ constante geral; $\mathrm{N}_{i}=$ efeito do nível de energia $\mathrm{i}$, em que $\mathrm{i}=$ 2.410; 2.450; 2.490; 2.530 e 2.570 kcal de energia líquida/kg; $\mathrm{G}_{j}=$ efeito do sexo j (1 = macho, 2 = fêmea); $\mathrm{N} \times \mathrm{G}=$ interação nível de energia líquida e sexo; $\mathrm{e}_{i j k}=$ erro aleatório associado a cada observação.

Os graus de liberdade referentes aos níveis de energia líquida foram desdobrados em polinômios e, para as variáveis que apresentaram efeito quadrático, foram feitas as derivações das equações para obtenção do melhor nível de energia líquida.

\section{Resultados e Discussão}

Não houve efeito $(\mathrm{P}>0,05)$ das relações treonina:lisina digestíveis das rações sobre os teores de proteína bruta fecal (PBF), proteína bruta na urina (PBU) e proteína bruta total excretada (PBTE) e sobre o valor biológico da proteína dietética (VBPD) (Tabela 4). Entretanto, houve efeito $(\mathrm{P}<0,05)$ quadrático das relações treonina:lisina digestíveis sobre os valores de proteína bruta absorvida (PBAB), proteína bruta retida (PBR) e nitrogênio da uréia plasmática (NUP). Do mesmo modo, as relações treonina:lisina das rações tiveram efeito quadrático $(\mathrm{P}=0,06)$ sobre a utilização líquida da proteína (ULP), semelhante às demais variáveis. Os efeitos quadráticos das relações treonina:lisina das rações provavelmente estão relacionados à melhora no perfil de aminoácidos da dieta, o que permitiu maior absorção, retenção e utilização líquida da proteína. Na derivação das equações obtidas para PBAB, PBR, ULP e NUP (Figura 1), obtiveram-se os valores de 0,652; 0,642; 0,642 e 0,673, respectivamente. Esses resultados são semelhantes aos reportados por Paiano et al. (2007), que obtiveram efeito quadrático das relações treonina:lisina digestíveis sobre a proteína excretada, a proteína retida e a utilização líquida da proteína em leitões dos 15 aos 30 kg, criados em condições semelhantes às deste estudo.

Valores baixos de NUP estão relacionados a melhor utilização de nitrogênio para a deposição de tecido (Coma et al., 1995), o que confirma a melhora no perfil de aminoácidos, que aumenta a retenção e reduz a excreção de nitrogênio.

A utilização líquida média de proteína (fração de nitrogênio retido em relação ao consumido) de 52\% obtida 
Tabela 4 - Proteína bruta (PB) consumida, PB fecal, PB absorvida, PB da urina, PB total excretada, PB retida, utilização líquida de proteína (ULP), valor biológico da proteína dietética (VBPD) e nitrogênio da uréia plasmática (NUP) de suínos em crescimento $(30$ a $60 \mathrm{~kg})$

\begin{tabular}{|c|c|c|c|c|c|c|c|c|}
\hline \multirow[b]{2}{*}{ Item } & \multicolumn{5}{|c|}{ Relação TL } & \multirow[t]{2}{*}{ Média \pm DP } & \multirow[t]{2}{*}{$\mathrm{CV}^{1}$} & \multirow[t]{2}{*}{ Efeito $^{2}$} \\
\hline & 0,574 & 0,624 & 0,673 & 0,722 & 0,772 & & & \\
\hline PB consumida, g/dia & 174,15 & 173,60 & 169,29 & 175,26 & 161,93 & $170,85 \pm 16,32$ & - & - \\
\hline PB fecal, g/dia & 27,32 & 26,95 & 24,06 & 25,92 & 25,98 & $26,04 \pm 4,01$ & 9,76 & NS \\
\hline PB absorvida, g/dia & 146,83 & 146,65 & 145,24 & 149,34 & 135,95 & $144,80 \pm 13,04$ & 3,46 & $\mathrm{Q}=0,03$ \\
\hline PB da urina, g/dia & 56,16 & 54,41 & 53,08 & 59,38 & 61,01 & $56,81 \pm 10,24$ & 11,96 & NS \\
\hline PB total excretada, g/dia & 83,48 & 81,36 & 77,13 & 85,30 & 86,99 & $82,85 \pm 12,72$ & 7,73 & NS \\
\hline PB retida, g/dia & 90,66 & 92,24 & 92,16 & 89,96 & 74,94 & $87,99 \pm 9,68$ & 7,25 & $\mathrm{Q}=0,02$ \\
\hline ULP, \% & 52,24 & 53,09 & 54,67 & 51,46 & 46,63 & $51,62 \pm 4,56$ & 6,66 & $\mathrm{Q}=0,06$ \\
\hline VBPD, \% & 61,84 & 62,84 & 63,81 & 60,44 & 55,42 & $60,87 \pm 5,28$ & 7,10 & NS \\
\hline NUP, mg/dL & 15,17 & 14,24 & 12,28 & 13,44 & 15,57 & $14,14 \pm 1,64$ & 9,22 & $\mathrm{Q}=0,01$ \\
\hline
\end{tabular}

${ }^{1}$ Coeficiente de variacão; ${ }^{2}$ Análise de regressão: $\mathrm{Q}=$ efeito quadrático, $\mathrm{PBAB}=-166,75886+967,92325 \mathrm{TL}-742,34590 \mathrm{TL}^{2} ; \mathrm{PBR}=-348,88070+1379,60116$ TL - 1073,80700 TL² ; ULP = -130,14646 + 573,94140 TL - 446,69120 TL²; NUP = 133,21478 - 357,84676 TL + 265,94860 TL²; NS - não-significativo.

$\mathrm{PBAB}=-166,75886+967,92325 \mathrm{TL}-742,34590 \mathrm{TL}{ }^{2}$

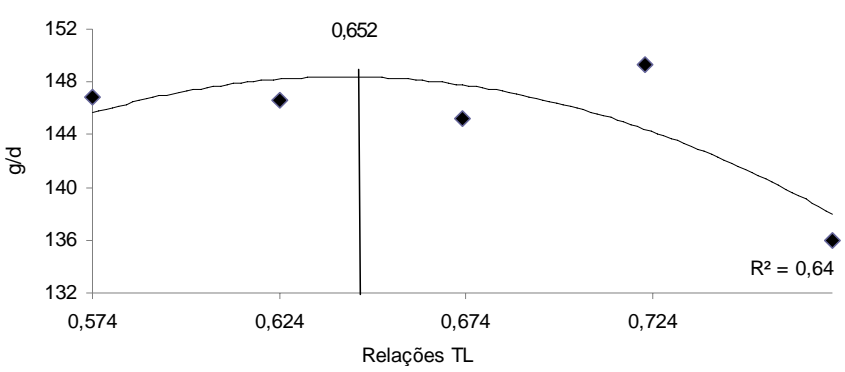

ULP $=-130,14646+573,94140 T L-446,69120 T L^{2}$

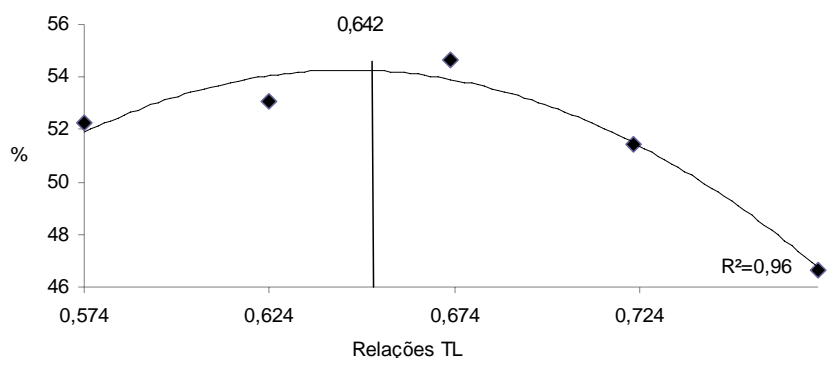

$\mathrm{PBR}=-348,88070+1379,60116 \mathrm{TL}-1073,80700 \mathrm{TL}^{2}$

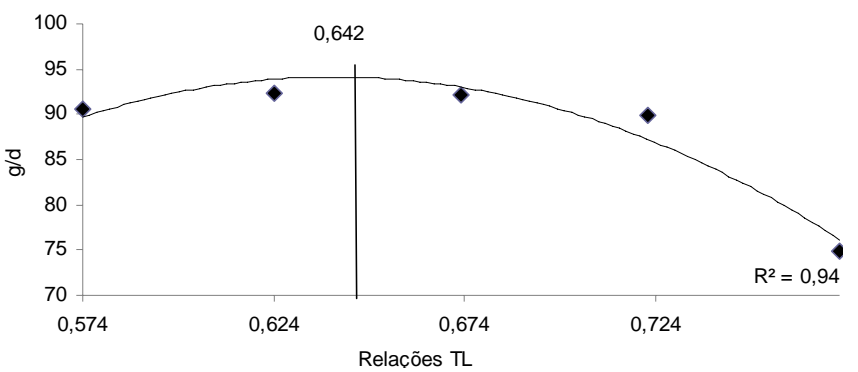

NUP $=133,21478-357,84676 \mathrm{TL}+265,94860 \mathrm{TL}^{2}$

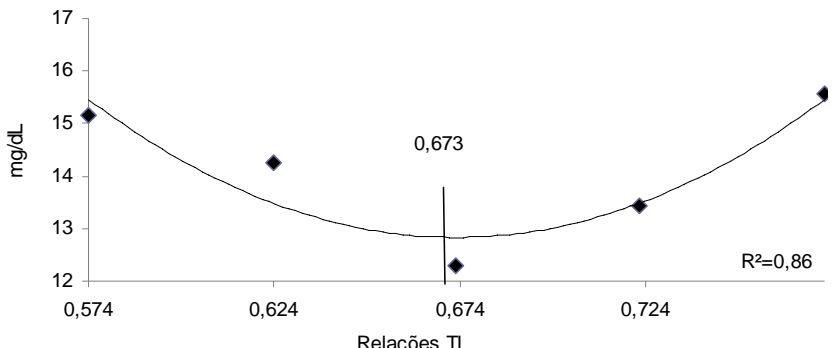

Figura 1 - Proteína bruta (PB) absorvida, PB retida (PBR), utilização líquida da proteína (ULP) e nitrogênio da uréia plasmática (NUP) de suínos em crescimento (30 a $60 \mathrm{~kg}$ ).

neste experimento foi maior que os valores de 30 a $40 \%$, geralmente observados na literatura (Oliveira, 2001). Contudo, foram utilizadas dietas de baixo teor de proteína bruta (3\% inferior ao do NRC, 1998), calculado com base no conceito de proteína ideal. Em estudo sobre o balanço de nitrogênio, Le Bellego et al. (2001) observaram ULP de 49,7\% em animais alimentados com rações com 16,7\% de PB e registraram redução de $37 \%$ na excreção de nitrogênio com a redução do teor de PB de 18,9 para 14,6\% em animais de $65 \mathrm{~kg}$ de peso vivo.
A relação treonina:lisina digestíveis para máxima $\mathrm{PBAB}$, PBR e ULP foi semelhantes à indicada pela Ajinomoto (2003), de 0,650, em compilação de dados de experimentos. Os resultados obtidos para a redução do NUP também foram semelhantes aos reportados por Murphy (1998), de 0,670, para suínos dos 20 aos $50 \mathrm{~kg}$.

A recomendação final, de 0,658 , foi obtida pela média da PBR e do NUP. Essas duas variáveis foram tomadas como referência por apresentarem as melhores significâncias $(\mathrm{P}<0,02 ; \mathrm{P}<0,01)$ e por serem variáveis obtidas em análises 
laboratoriais independentes, ao contrário das variáveis resultantes do balanço de nitrogênio, cujos possíveis erros inerentes ao experimento e à precisão das análises laboratoriais estão contidas em todas as variáveis.

No período de crescimento, os machos apresentaram maior $(\mathrm{P}<0,05)$ consumo diário de ração, ganho diário de peso e NUP. Entretanto, não houve $(\mathrm{P}>0,05)$ efeito do sexo sobre a conversão alimentar nem dos níveis de energia líquida sobre as variáveis nesta fase (Tabela 5).

No período de terminação, os machos apresentaram maior $(\mathrm{P}<0,05)$ consumo diário de ração e NUP epior conversão alimentar, mas o ganho de peso diário foi o mesmo $(\mathrm{P}>0,05)$ observado nas fêmeas. Houve efeito linear decrescente $(\mathrm{P}<0,05)$ dos níveis de energia líquida sobre o consumo diário de ração, assim como melhora linear na conversão alimentar. Não houve interação $(\mathrm{P}>0,05)$ níveis de energia líquida $\times$ sexo dos animais para as características de desempenho nas fases de crescimento e de terminação dos animais (Tabela 5).

No período total (30 a $90 \mathrm{~kg}$ ), os machos apresentaram $(\mathrm{P}<0,05)$ maior consumo diário de ração e ganho de peso diário. Houve interação $(\mathrm{P}<0,05)$ sexo $\times$ nível de energia líquida para o ganho de peso diário e, apesar dessa interação, no período total, as análises de regressão não indicaram efeito dos níveis de energia líquida sobre esta variável. O aumento do nível de energia líquida das rações ocasionou redução linear $(\mathrm{P}<0,05)$ no consumo diário de ração e melhora linear $(\mathrm{P}<0,05)$ na conversão alimentar (Tabela 5).

A ausência de efeitos de níveis energéticos na fase de crescimento e os efeitos na fase de terminação e no período total confirmam resultados observados por Bikker \& Bosch (1996) de que os níveis energéticos da ração tiveram efeitos mais pronunciados em animais na fase de terminação que naqueles em fase de crescimento.

A melhora na conversão alimentar nos períodos de terminação e total foi semelhante aos resultados descritos por Silva et al. (1998), que, estudando diferentes níveis de energia digestível para suínos machos não-castrados na fase dos 60 a 100 kg, observaram melhora na conversão alimentar com o aumento dos níveis de energia da dieta.

Os maiores consumos diários de ração nos suínos machos corroboram os resultados obtidos por Hale et al. (1968) e Patience et al. (2007), que também observaram maior ganho de peso diário nas fases inicial e total e pior conversão alimentar na fase final em experimentos para avaliação dos efeitos dos níveis de energia da dieta e do sexo sobre o desempenho dos animais.

Houve interação sexo $\times$ nível de energia líquida da dieta $(\mathrm{P}<0,05)$ para o peso de abate (PABAT) e o peso do pernil 
(PERNIL), do mesmo modo que houve interação ( $\mathrm{P}=0,06 \mathrm{e}$ $0,07)$ para peso da carcaça resfriada (PCRSF) e para o rendimento de carcaça (RENCAR) (Tabela 6).

Os machos castrados apresentaram maiores $(\mathrm{P}=0,01)$ médias para o peso de abate e o peso da carcaça resfriada, contudo, apresentaram também piores valores de espessura e profundidade de toucinho, porcentagem de carne magra na carcaça e gordura abdominal em comparação às fêmeas (Tabela 6). Esses resultados são semelhantes aos reportados por Vieira et al. (2004), que, avaliando níveis de energia líquida para machos e fêmeas, encontraram valores inferiores para espessura de toucinho e superiores para a porcentagem de carne magra nas fêmeas, independentemente do nível de energia líquida da dieta.

Os níveis de energia líquida da dieta tiveram efeito $(\mathrm{P}<0,05)$ quadrático (com ponto de máximo no nível de $2.517 \mathrm{kcal} / \mathrm{kg}$ de ração) sobre a profundidade de toucinho, efeito linear crescente $(P=0,08)$ sobre a espessura de toucinho no crescimento e efeito linear crescente $(\mathrm{P}=0,05)$ sobre a gordura abdominal. O nível de energia líquida não influenciou $(\mathrm{P}>0,10)$ as demais características de carcaça (Tabela 6).

Esses resultados diferem dos reportados por Bertol et al. (2001), que não encontraram efeitos dos níveis de energia digestível sobre a qualidade de carcaças de suínos de alto potencial genético para deposição de carne magra. Do mesmo modo, Dourmand \& Noblet (1998) relataram que animais melhorados para a deposição de carne magra estão menos sujeitos ao comprometimento da carcaça quando alimentados com rações com maiores níveis de energia ou submetidos à restrição alimentar. Entretanto, esses autores não trabalharam com dietas de baixo nível de proteína calculadas de acordo com o conceito de proteína ideal. Neste tipo de dieta, o baixo nível de proteína aumenta ainda mais a quantidade de energia líquida para os suínos, o que parece prejudicar as características de carcaça, mesmo em animais melhorados.

Essas afirmações foram confirmadas por Kerr et al. (1995) e Le Bellego et al. (2001), que observaram aumento na gordura das carcaças de suínos alimentados com dietas de baixo nível protéico, resultados que indicam que o aumento no nível de energia líquida, embora melhore a conversão alimentar, pode prejudicar algumas características da carcaça de suínos.

Não houve $(\mathrm{P}>0,05)$ efeitos dos níveis de energia, do sexo e da interação sexo $\times$ nível de energia para a perda por gotejamento, o pH e os teores de matéria seca, matéria mineral e proteína bruta do músculo Longissimus dorsi, logo, os níveis estudados não foram suficientes para provocar diferenças nessas características da carcaça (Tabela 7). 
No entanto, houve $(\mathrm{P}<0,05)$ interação sexo $\times$ nível de energia líquida sobre o marmoreio e efeito $(\mathrm{P}<0,05)$ quadrático com ponto de máximo para as fêmeas ( $2.493 \mathrm{kcal} /$ kg de ração). O efeito dos níveis de energia sobre o marmoreio das fêmeas confirma afirmações de Latorre et al. (2004) de que o sexo pode influenciar o desempenho na fase de crescimento e, principalmente, na fase de terminação, o que altera o padrão de deposição de tecido magro e de gordura entre os machos e as fêmeas.

\section{Conclusões}

A melhor relação treonina:lisina digestíveis para suínos em crescimento e terminação é 0,658 , pois melhora a utilização do nitrogênio. $\mathrm{O}$ aumento da energia líquida das dietas de 2.410 para $2.570 \mathrm{kcal} / \mathrm{kg}$ reduz o consumo, melhora a conversão alimentar e aumenta a gordura abdominal.

\section{Literatura Citada}

ADEOLA, O. Digestion and balance techniques in pigs. In: LEWIS, A.J.; SOURTHERN, L.L. (Eds.) Swine nutrition. 2.ed. Boca Raton: CRC, 2001. p.903-916.

AJINOMOTO [2003]. Exigências de treonina para suínos benefícios da suplementação de L-treonina. Disponível em:<http://www.lisina.com.br/upload/bibliografia/IT_10_port. pdf $>$ Acesso em: 24/6/2006.

ASSOCIAÇÃO BRASILEIRA DE CRIADORES DE SUÍNOS - ABCS. Método brasileiro de classificação de carcaça. Estrela: 1973. 17p. (Publicação Técnica, 2).

BERTOL, T.M.; LUDKE, J.V.; BELLAVER, C. Efeito do peso do suíno em terminação ao início da restrição alimentar sobre o desempenho e a qualidade da carcaça. Revista Brasileira de Zootecnia, v.30, n.2, p.417-424, 2001

BIKKER, P.; BOSCH, M. Nutrient requirements of pigs with high genetic potential for lean gain. In: SIMPÓSIO INTERNACIONAL SOBRE EXIGÊNCIAS NUTRICIONAIS DE AVES E SUÍNOS, 1996, Viçosa, MG. Anais... Viçosa, MG: Universidade Federal de Viçosa, 1996. p.223-239.

BOCCARD, R.; BUCHTER, L.; CASSELS, E. et al. Proceedings for measuring meat quality characteristics in beef production experiments. Livestock Production Science, v.8, p.385-397, 1981.

COMA, J.; CARRION, D.; ZIMMERMAN, D.R. Use of plasma urea nitrogen as a rapid response criterion to determine the lysine requirement of pigs. Journal of Animal Science, v.73, p.472481,1995

DEFA, L.; CHANGTING, X.; SHIYAN, Q. et al. Effects of dietary threonine on performance, plasma parameters and immune function of growing pigs. Animal Feed Science and Technology, v.78, p.179-188, 1999.

DOURMAD, J.Y.; NOBLET, J.A. Genetics, environment and nutrition interrelationship in swine production. In: SIMPÓSIO SOBRE NUTRIÇÃO ANIMAL E TECNOLOGIA DA PRODUÇÃO DE RAÇÕES, 1998, Campinas. Anais... Campinas: 1998. p.155-158.

HALE, M.; JOHNSON, J.C.; WARREN, E.P. Influence of season, sex and dietary energy concentration on performance and carcass characteristics of swine. Journal of Animal Science, v.27, p.1577-1582, 1968.

KERR, B.J.; MCKEITH, F.K.; EASTER, R.A. Effect of performance and carcass characteristics of nursery to finisher pigs fed reduced 
crude protein, amino acid-supplemented diets. Journal of Animal Science, v.73, p.433-440, 1995.

LATORRE, M.A.; LÁZARO, R.; VALENCIA, D.G. et al. The effects of gender and slaughter weight on the growth performance, carcass traits, and meat quality characteristics of heavy pigs. Journal of Animal Science, v.82, p.526-533, 2004.

LE BELLEGO, L.; MILGEN, J.V.; DUBOIS, S. et al. Energy utilization of low-protein diets in growing pigs. Journal of Animal Science, v.79, p.1259-1271. 2001.

MARSH, W.H.; FINGERHUT, B.; MILLER, H. Automated and manual direct methods for determination of blood urea. Clinical Chemistry, v.11, n.6, p.624-627, 1965.

MURPHY, J. [1998]. Advances in swine nutrition to address nutrient management issues. Disponível em: <http://www.omafra. gov.on.ca/english/livestock/swine/facts/nmannutr.htm> Acesso em: 24/6/2006.

NATIONAL PORK PRODUCERS COUNCIL - NPPC. Procedures to evaluate market hogs. 3.ed. Des Moines: 1991. 16p.

NOBLET, J. Net energy for growth in pigs: application to low protein, amino acid supplemented diets. In: PORK INDUSTRY CONFERENCE, 1996, Urbana. Proceedings... Urbana: University of Illinois, 1996. p.15-25.

NOBLET, J.; HENRY, Y.; DUBOIS, S. Effect of protein and lysine levels in the diet on body gain composition and energy utilization in growing pigs. Journal of Animal Science, v.65, p.717-726, 1987.

NATIONAL RESEARCH COUNCIL - NRC. Nutrient requirements of swine. 10.ed. Washington, D.C.: 1998. 189p.

OLIVEIRA, P.A.V. Produção e manejo de dejetos suínos. In: SOARES, W.R. (Ed.) A produção animal na visão dos brasileiros. Piracicaba: Fundação de Estudos Agrários Luiz de Queiroz, 2001. p.164-177.
PAIANO, D.; MOREIRA, I.; SILVESTRIN, N. et al. Balanço de nitrogênio de suínos na fase inicial recebendo dietas com diferentes relações treonina:lisina digestíveis. In: CONGRESSO DA ASSOCIAÇÃO BRASILEIRA DE VETERINÁRIOS ESPECIALISTAS EM SUÍNOS, 13., 2007, Florianópolis. Anais... Concórdia: Embrapa Suínos e Aves, 2007. (CD-ROM).

PATIENCE, J.F.; BEAULIEU, A.D.; ZIJLSTRA, R.T. [2007]. Response to growing-finishing pigs to dietary energy concentration. Disponível em: <http://www.thepigsite.com/ articles/3/feed-nutrition-and-water/1264/response-to-growing finishing-pigs-to-dietary-energy-concentration> Acesso em: $12 / 7 / 2007$

RODRIGUES, N.E.B.; DONZELE, J.L.; OLIVEIRA, R.F.M. et al. Níveis de treonina em rações para leitoas com alto potencial genético para a deposição de carne magra dos 30 aos $60 \mathrm{~kg}$. Revista Brasileira de Zootecnia, v.30, n.6, p.2039-2045, 2001.

ROSTAGNO, H.S.; ALBINO, L.F.T.; DONZELE, J.L. et al. Tabelas brasileiras para aves e suínos: composição de alimentos e exigências nutricionais. 2.ed. Viçosa, MG: Editora UFV, 2005. 186p.

SILVA, D.J.; QUEIROZ, A.C. Análise de alimentos: métodos químicos e biológicos. 3.ed. Viçosa, MG: Editora UFV, 2002. 235p.

SILVA, F.C.O.; DONZELE, J.L.; FREITAS, R.T.F. et al. Níveis de energia digestível para suínos machos inteiros dos 60 aos 100 kg. Revista Brasileira de Zootecnia, v.27, n.5, p.959964, 1998.

VIEIRA, A.A.; BARBOSA, H.C.A.; ALMEIDA, F.Q. et al. Qualidade da carcaça de suínos machos e fêmeas, abatidos em diferentes pesos, alimentados com dieta contendo dois níveis de energia líquida, sob restrição alimentar na fase de terminação. Revista da Universidade Rural Rio de Janeiro, v.24, n.1, p.155$160,2004$. 